\title{
Perceptions of Adolescents, Teachers and Parents of Life Skills Education and Life Skills in High School Students in Hong Kong
}

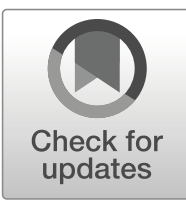

\author{
Daniel T.L. Shek ${ }^{1}$ (D) $\cdot$ Li Lin $^{1} \cdot$ Cecilia M.S. Ma ${ }^{1} \cdot$ Lu Yu $^{1} \cdot$ Janet T.Y. Leung ${ }^{1} \cdot$ \\ Florence K.Y. Wu ${ }^{2} \cdot$ Hilde Leung $^{3} \cdot$ Diya Dou $^{1}$
}

Received: 13 April 2020 / Accepted: 25 May 2020 / Published online: 12 June 2020

(C) The Author(s) 2020

\begin{abstract}
Although theories and research emphasize the importance of adolescent life skills, different stakeholders' perceptions of the related issues have not been systematically investigated, particularly in Chinese contexts. This paper presents and integrates findings from four studies examining perceptions of different stakeholders on the need for and adequacy of life skills education and perceived adolescent life skills in Hong Kong. Data from four studies were used, including a longitudinal study with senior high school students $(N=3328+)$ and three cross-sectional studies based on students $(N=2474)$, teachers $(N=568)$ and parents $(N=431)$. Participants responded to measures on their perceptions of the need for life skills education and adequacy of related education in the formal curriculum. They also rated adolescent life skills in different domains, including emotional competence, moral competence, resilience, problemsolving, life meaning, gratefulness, social competence, and integrity. Consistent across the four studies, while many stakeholders regarded life skills as important for adolescents, a majority of them also perceived life skills education as insufficient in the school curriculum. There were also views suggesting that adolescent life skills development was incomplete. Compared with teachers and parents, adolescents perceived higher levels of life skills in themselves and adolescents in Hong Kong. There is a strong perceived need to step up life skills education in adolescents, particularly in Hong Kong.
\end{abstract}

Keywords Life skills · Psychosocial competencies · Adolescent well-being · Chinese adolescents $\cdot$ Hong Kong · Adolescent thriving

Daniel T.L. Shek

daniel.shek@polyu.edu.hk

Extended author information available on the last page of the article 


\section{Introduction}

The concept of "life skills" or "soft skills" have received much attention from professionals in different fields in the past two decades. According to the World Health Organization (WHO 2009, p. 3), life skills are the building block of adolescent health which includes "dealing with conflict that cannot be resolved, dealing with authority, solving problems, making and keeping friends/relationships, cooperation, self-awareness, creative thinking, decision-making, critical thinking, dealing with stress, negotiation, clarification of values, resisting pressure, coping with disappointment, planning ahead, empathy, dealing with emotions, assertiveness, active listening, respect, tolerance, trust, sharing, sympathy, compassion, sociability, self-esteem”. Similarly, UNESCO (2016) stressed the importance of life skills in different contexts ("transversal skills") which includes critical and innovative thinking, intrapersonal skills, interpersonal skills, global citizenship, and media and information literacy.

The importance of life skills in adolescent development is intrinsic to many models of adolescent development (Shek et al. 2019b). In the developmental asset model (Benson et al. 2011), the focus is on different developmental assets such as positive values and social competencies. In the $5 \mathrm{C} / 6 \mathrm{C}$ models, the focus is put on confidence, competence, connection, care/compassion and contribution (Lerner et al. 2011). In the social-emotional learning framework advocated by the Collaborative for Academic, Social and Emotional Learning (CASEL; https://casel.org), self-awareness, selfmanagement, social awareness, relationship skills and responsible decision-making are important adolescent psychosocial competencies. With reference to the positive youth development approach, Catalano et al. (2004) highlighted a number of life skills in adolescents, including emotional competence, social competence, moral competence, spirituality, and resilience. In fact, the concept of life skills (psychosocial competence or soft skills) is endorsed by different professionals, including youth workers, social workers, psychologists, pediatricians and allied health workers. As such, it is important to understand whether knowledge of these psychosocial competences is adequately covered in the school context. This is exactly why we integrated the findings of several studies.

Empirically, many studies showed that life skills were positively related to positive adolescent development and negatively related to adolescent risk behavior (Domitrovich et al. 2017). For example, Sun and Shek (2012) showed that positive youth development attributes negatively predicted adolescent problem behavior over time. Shek and Lin (2017b) also showed that positive youth development attributes negatively predicted the use of foul language in high school students. Review studies also show that life skills programs can promote holistic development in adolescents, including psychosocial competencies and academic outcomes (Catalano et al. 2012; Harris and Cheney 2018; January et al. 2011; Taylor et al. 2017).

Unfortunately, existing studies on life skills have been predominately conducted in Western societies (Nasheeda et al. 2019), with very few studies in non-Western societies. With particular reference to the Chinese culture, academic success has been traditionally regarded as an important way to climb up the social ladder. Hence, Chinese parents strongly emphasize scholastic competence in children and adolescents at the expense of other areas of development, such as life skills (Shek and Siu 2019a). 
Another limitation of the related scientific literature involves a lack of studies examining the perceptions of different stakeholders (including students, teachers and parents) of adolescent life skills and related education, especially in the formal curriculum. Although some studies examined the perceptions of different stakeholders on life skills programs (i.e., subjective outcome evaluation) (Ferrari et al. 2004; Meyer and Wurdinger 2016; Prajapati et al. 2017), no scientific findings have been reported on how different stakeholders perceive life skills in different Chinese contexts. There are two reasons why we should understand the views of different stakeholders. First, the related findings can help to enrich our understanding of the related phenomena and facilitate theory development (e.g., parent-child discrepancies in the perceived importance of life skills). Second, listening to the voices of different stakeholders can help to reinforce policies and services on the promotion of life skills in adolescents. This is in line with the spirit of "partners in life skills education" advocated by the World Health Organization (WHO 2009). To fill these research gaps, we addressed several research questions in this paper:

1. What are the perceptions of students, teachers and parents of the need for life skills education for adolescents? Do the perceptions of students differ across different grades? As Grade 11 and Grade 12 students display more academic stress and poorer well-being, it was predicted that Grade 11 and 12 students would see a higher need for life skills education than did Grade 10 students (Hypothesis 1).

2. What are the perceptions of students, teachers and parents on the adequacy of life skills education in the formal curriculum? Do the perceptions differ amongst different grades? As the focus on examination is stronger in Grade 11 and Grade 12, it was expected that Grade 11 and Grade 12 students would regard life skills education as more insufficient than did Grade 10 students (Hypothesis 2).

3. What are the perceptions of students, teachers and parents on the life skills development in adolescents in Hong Kong? Do the perceptions differ across different stakeholders? Based on the literature on self-enhancement (Alicke and Sedikides 2009), we hypothesized that students would perceive life skills in themselves and young people in Hong Kong to be more favorable than did those of teachers and parents (Hypothesis 3).

In this paper, we reported and integrated the findings from four studies. The first study was a longitudinal study based on the responses of Grade 10 to Grade 12 students. In the next three cross-sectional studies, we examined the perceptions of students, teachers and parents of the need for and adequacy of life skills education as well as their perceptions of life skills in adolescents in Hong Kong. All studies were approved by the institutional review board on survey ethics of The Hong Kong Polytechnic University.

\section{Study 1}

The first study was a 6-year longitudinal study examining the personal, family and school adjustment of high school students in Hong Kong. Through stratified cluster sampling method, we recruited 28 schools, with 3328 students at Wave 1 (Shek and Lin 2017a). There were several parts in the questionnaire, including measures of positive youth development (Shek and Lin 2017a, b), well-being (Shek and Liang 2018; Shek 
and Lin 2017), risk behavior (Shek et al. 2019a, 2020) and family processes (Shek and Zhu 2019). In the questionnaire, we also assessed students' perceptions of life skills education in senior high school years.

\section{Method}

A single item was used to assess senior high school (i.e., Grade 10 to Grade 12) students' perception of the need for life skills education ("Do you think it is necessary for Hong Kong adolescents to learn knowledge of life skills?), with the response options of "Extremely unnecessary" (1), "Unnecessary" (2), "Necessary" (3) and "Extremely necessary" (4). Besides, another item on the adequacy of life skills education in the formal curriculum was asked ("Do you think the knowledge of life skills you have learned in the formal school curriculum is sufficient?") with four response options: "Extremely insufficient" (1), "Insufficient" (2), "Sufficient" (3) and "Extremely sufficient" (4). School, parental and student consent was obtained before the commencement of the study.

\section{Results and Discussion}

Several observations based on response frequencies can be highlighted (Table 1). First, an overwhelming majority of the students (over 93\% in the three grades) perceived that there was a need for Hong Kong adolescents to learn life skills. Second, compared to Grade 10 students, Grade 11 and Grade 12 students perceived the necessity of having life skills knowledge to be greater, hence supporting Hypothesis 1. Third, many students perceived that the life skills knowledge that they had learned from the formal school curriculum was insufficient (34.3\% in Grade 10 students, $43.3 \%$ in Grade 11 students and $43.8 \%$ in Grade 12 students). Fourth, Grade 11 and Grade 12 students saw the insufficiency to be greater than did the Grade 10 students, providing support for Hypothesis 2.

The findings strongly suggest that there is a huge gap in life skills education in Hong Kong. While almost all students perceived life skills knowledge as important, one-third to around $44 \%$ of the students in different grades perceived life skills education in the formal school curriculum as insufficient. Obviously, this observation poses a big challenge for policy makers and school administrators. This study also showed that Grade 11 and Grade 12 students perceived a greater need for and insufficiency of life skills education in the formal curriculum. This can be explained by greater academic stress, a rise in hopelessness, and a drop in life satisfaction experienced by Grade 11 and Grade 12 students (Shek and Liang 2018). Again, this calls for policy and services response from the Government and the education sector.

\section{Study 2}

In the second study, we examined the views of students regarding the need for and adequacy of life skills education in the formal curriculum. Besides, we also studied students' perceptions of life skills in themselves and moral competence in Hong Kong adolescents (Shek and Lin 2017a; Shek et al. 2019c). 


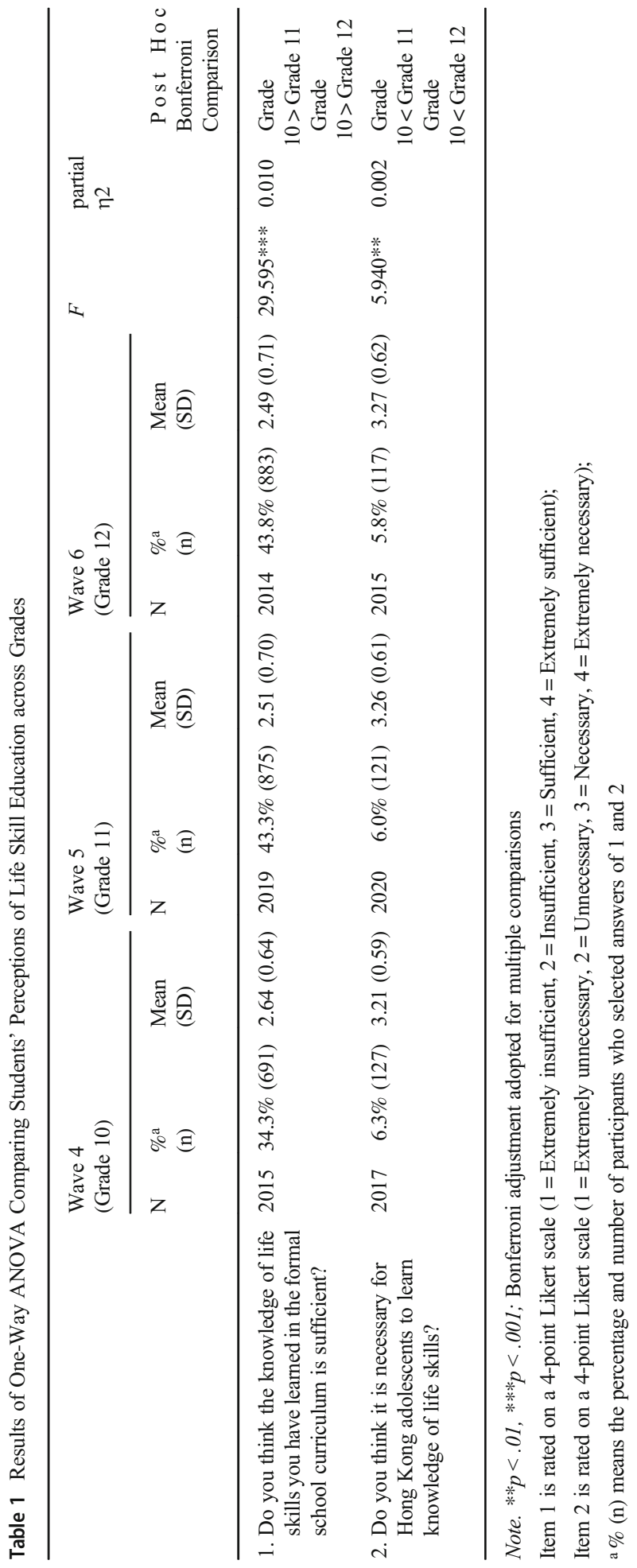




\section{Method}

We recruited 2474 students (Mean age $=14.76, \mathrm{SD}=1.82 ; 1271$ females and 1123 males; 1336 Grade 7 to Grade 9 students; 906 Grade 10 to Grade 12 students) from 20 local secondary schools admitting students with different levels of academic performance. School, parental and student consent was obtained before the data collection. Students responded to the following measures:

Need for Life Skills A single question was used to assess the perceived need for life skills ("Do you think it is necessary for Hong Kong adolescents (12-18 years old) to acquire life skills?") with four response options: "Very unnecessary" (1), "Unnecessary" (2), "Necessary" (3), and "Very necessary" (4).

Adequacy of Life Skills Knowledge A single question was employed to assess perceived sufficiency of life skills education ("Do you think Hong Kong adolescents (12-18 years old) have adequate knowledge of life skills in current formal school curriculum?') with four choices: "Very inadequate" (1), "Inadequate" (2), "Adequate" (3), and "Very adequate" (4).

Adolescent Life Skills a total of eight items were used to assess the perceived development of life skills in adolescents in Hong Kong (emotional competence, moral competence, resilience, problem-solving ability, having ideals or aspirations, gratefulness, interpersonal competence and integrity) with five response options: "Very weak" (1), "Weak" (2), "Average" (3), "Strong" (4), and "Very strong" (5). Three additional items were used to understand moral competence in adolescents: 1. "Do you think the moral competence of Hong Kong adolescents (12-18 years old) is high or low?" with five possible answers: "Very low" (1), "Low" (2), "Neither high nor low" (3), "High" (4), and "Very high" (5); 2. "Do you think the moral competence of Hong Kong adolescents (12-18 years old) are gradually going upwards, downwards, or similar to the past?" with three response options: "Going downwards gradually" (1), "Going upwards gradually" (2), and "Similar to the past" (3); 3. "Do you agree that it is more important for adolescents to have good moral character than excellent academic results?" with four response options: "Strongly disagree" (1), "Somewhat Disagree" (2), "Somewhat Agree" (3), and "Strongly agree" (4).

\section{Results and Discussion}

Several observations can be highlighted. First, while more than $90 \%$ of the students perceived the importance of life skills knowledge, around $18 \%$ felt that life skills education was not adequate (Table 2). Second, significant proportions of the students perceived life skills in adolescents to be weak in the areas of emotional competence (35\%), moral competence (31\%), resilience $(40.7 \%$ ), and problem-solving ability (30.2\%; Table 3 ). Third, although around $87 \%$ of the respondents regarded moral character as more important than academic results, one-fifth of the students perceived that moral competence of adolescents was low. Besides, one-third perceived that the morality of adolescents would drop in the future. Three conclusions can be drawn from Study 2. First, most students regarded life skills education and moral character as important. Second, compared to Study 1, comparatively fewer students in this study perceived that the related education in the formal curriculum was insufficient. Third, almost one-third of 
the respondents interestingly predicted a decline in adolescent morality in the future, which echoed the concerns about the psychosocial competence of adolescents (e.g., emotional management, resilience and problem-solving skills).

\section{Study 3}

One serious weakness of the existing studies on adolescent life skills is that studies have been conducted exclusively on adolescents. As such, we conducted another crosssectional study based on the responses of the teachers, which can provide an alternative perspective of related issues (Shek and Ma 2017; Shek et al. 2019d).

\section{Method}

We recruited 568 teachers from 11 secondary schools in Hong Kong. These 11 high schools were drawn from the schools that participated in Study 2. School and teacher consent was obtained before the data collection. Teachers responded to the same measures used in Study 2 which assessed the participants' perceptions of: a) the need for life skills (one item), b) adequacy of life skills knowledge in the formal curriculum (one item), and c) the perceived development of life skills in adolescents in Hong Kong (eight items).

\section{Results and Discussion}

Similar to Studies 1 and 2, most teachers (96.9\%) regarded life skills knowledge as important. However, $72.2 \%$ of the teachers pointed out that life skills education was insufficient in the formal curriculum (Table 3). As shown in Table 3, half or more than half of the teachers had the perception that students were weak in emotional management $(53.6 \%)$, resilience $(70.8 \%)$, problem-solving ability $(53.5 \%)$ and being grateful $(50.0 \%)$. Furthermore, although around $95 \%$ of the teachers considered moral character to be more important than academic results, roughly four-tenth of them regarded morality in Hong Kong adolescents as low and $67.3 \%$ predicted a decline in adolescent morality in the future. Finally, compared with students in Study 2, teachers perceived life skills knowledge to be more important than did students. They also held a less favorable perception of the adequacy of life skills in the formal curriculum and life skills in adolescents.

We can highlight several conclusions from this study. First, consistent with findings based on students, teachers endorsed the importance of life skills education and moral character in adolescents. They also pointed out the insufficiency of the related education in the formal curriculum, which echoed the previous findings (Shek et al. 2018; Shek and Leung 2018). Second, more than half of the teachers felt that psychosocial competence of adolescents, such as emotional management, resilience, problemsolving skills and gratefulness, were weak. Besides, teachers held negative perceptions of moral development in adolescents. Finally, teacher-student discrepancies were found, which were novel in the scientific literature on adolescent life skills.

\section{Study 4}

Parents play an important role in adolescent development. However, no study has been conducted to understand parents' perceptions of life skills in their adolescent children 


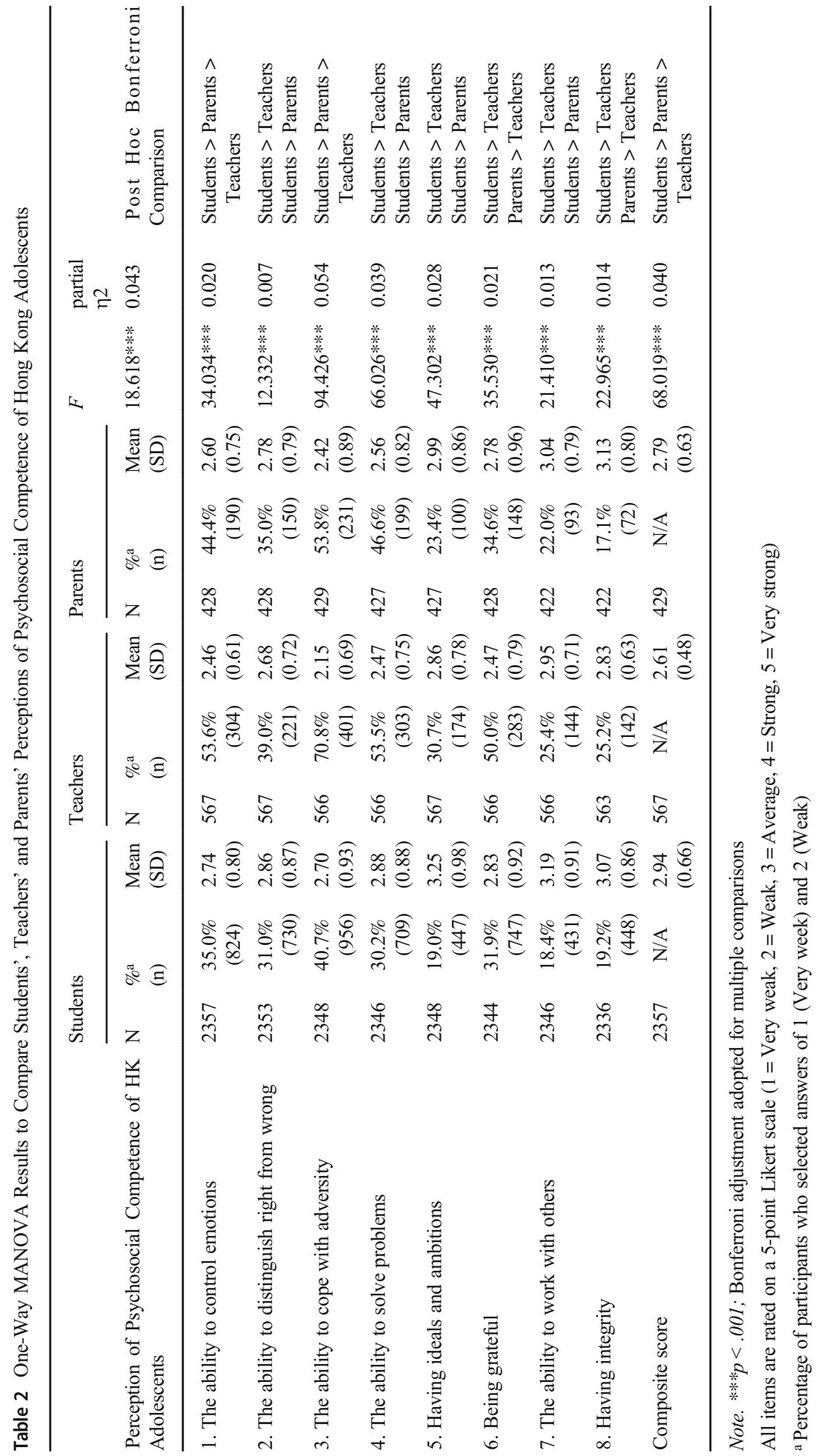




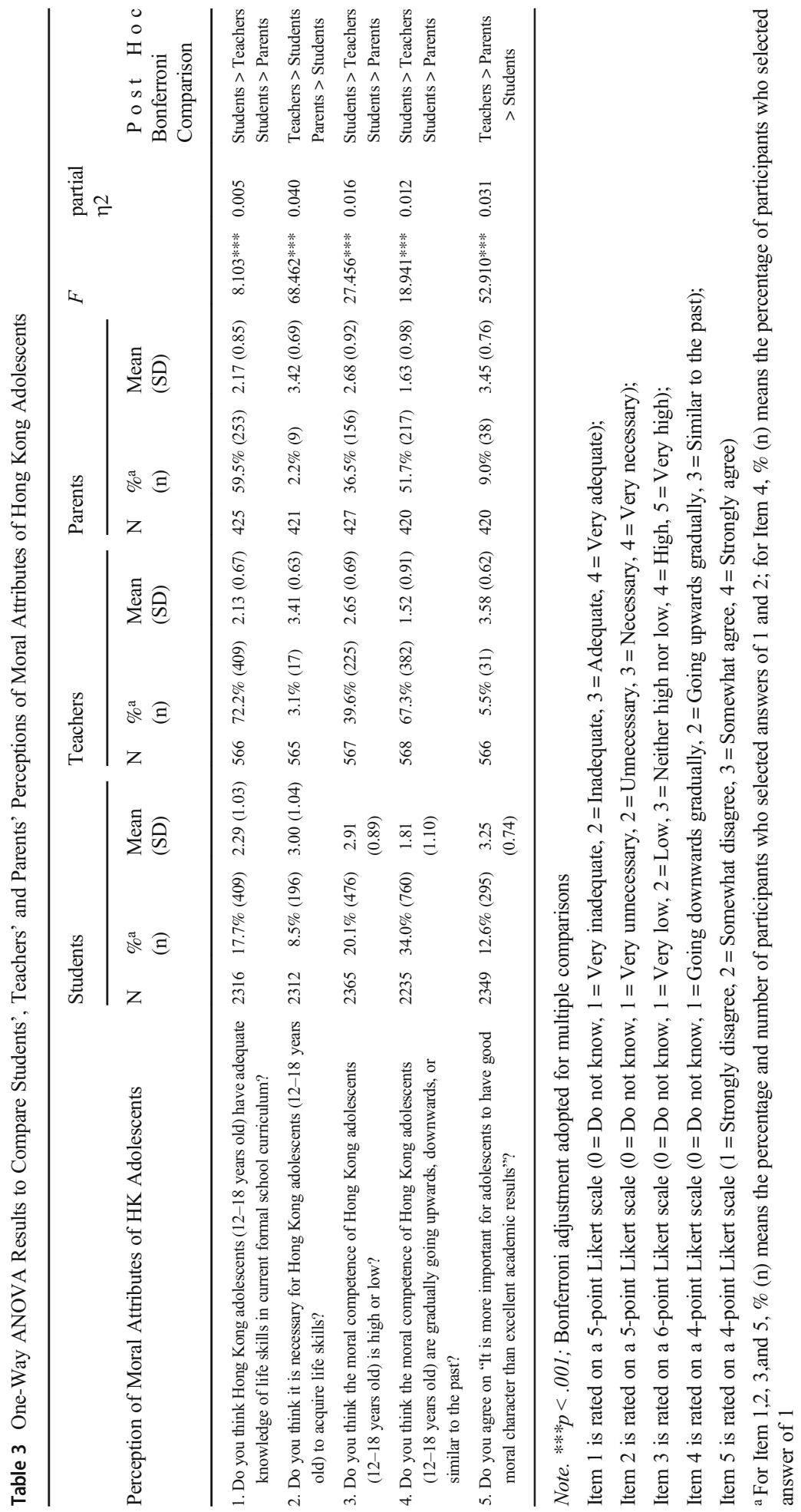


and Hong Kong adolescents. Therefore, we conducted another study to examine the perceptions of the parents, which enabled us to understand related issues from a third perspective (Shek and Yu 2018; Shek et al. in press).

\section{Method}

A total of 431 parents (mean age $=44.57$ ) were recruited from nine secondary schools that joined Study 2. The participants completed the questionnaire in a self-administered and anonymous manner. School and parental consent was obtained before the data collection. Parents responded to the same measures used in Study 2 (student sample) and Study 3 (teacher sample), which covered the need for life skills education (one question), adequacy of life skills education in the formal curriculum (one question), perceived adolescent life skills (eight items), and moral competence in adolescents (three questions).

\section{Results and Discussion}

Consistent with Study 1, Study 2 and Study 3, almost all parents (97.8\%) agreed that life skills knowledge was important. Also, similar to Study 1 and Study 3, a high proportion (around $60 \%$ ) of the parents perceived life skills education as insufficient in the formal curriculum (Table 2). Similar to Study 2 and Study 3, many parents perceived adolescents as weak in emotional management (44.5\%), resilience (53.8\%), problem-solving ability $(46.6 \%)$ and being grateful (34.6\%). Although roughly nine-tenth of the parents regarded moral character as important, $36.5 \%$ of them perceived adolescent morality to be low, and more than half $(51.7 \%)$ predicted a decline in adolescent morality in the future. Finally, parent-adolescent discrepancies on related issues were found. While parents perceived insufficiency of life skills knowledge to be higher than did students, adolescent children perceived adequacy of life skills in the formal curriculum and life skills to be more positive than parents' perceptions. These findings provide support for Hypothesis 3 .

Several common observations can be drawn across Studies 2, 3 and 4. First, different stakeholders regarded life skills and moral character as important. Second, many stakeholders, particularly adults, perceived that life skills education was insufficient in the formal curriculum. Third, concerns over life skills and moral competence were raised by many stakeholders. Finally, compared with adolescents, adults (teachers and parents) saw a greater need for and insufficiency of life skills education, and they saw life skills in adolescents to be weaker than adolescents' perception.

\section{General Discussion}

An integration of the findings based on the four studies revealed several phenomena which can be summarized by three "I"s: a) Importance: All stakeholders endorsed the importance of life skills in adolescents; b) Insufficiency: Different stakeholders, particularly teachers and parents, perceived that life skills education in the formal curriculum was insufficient; c) Incomplete adolescent development: Many stakeholders perceived weaknesses in life skills and moral development in adolescents.

The endorsement of the importance of life skills education is consistent with the propositions of international bodies (WHO 2009; UNESCO 2016) and theoretical models on youth development where development of life skills is emphasized (Shek et al. 2019a, 
2019b; Benson et al. 2011; Lerner et al. 2011; Catalano et al. 2004). Perceptions of the importance of life skills in adolescents also echo research on the positive impact of life skills and life skills programs on adolescent developmental outcomes. The consensus on the importance of life skills in adolescents clearly constitutes a solid foundation to develop policies and services on life skills education in adolescents.

Unfortunately, different stakeholders felt that the coverage of life skills education in the formal curriculum was insufficient. Although the proportion of students having this perception was not high in Study 2, the proportion was much higher amongst senior high school students in Study 1. This observation is in line with the view of Shek and Siu (2019b) that there is a lack of holistic adolescent education in Hong Kong. Again, this observation poses a challenge for policy makers and school administrators on how to address this gap in the formal curriculum.

There are several factors leading to the insufficiency of life skills in the formal curriculum. First, as Chinese culture strongly emphasizes academic excellence, the education system has focused on scholastic skills instead of soft skills, such as emotional competence and resilience. Actually, the education system in Hong Kong has been criticized as "super examination-oriented". Second, with a strong emphasis on success and achievement in Hong Kong, the education system is very pragmatic and the emphasis on whole person development is just lip service (Shek and Siu 2019b). Third, insufficiency in life skills education is contributed by the slow and non-responsive Government policy, as shown by the observation that soft skills and social-emotional learning are not emphasized in the Government education policies (Shek and Leung 2018; Shek and Siu 2019b).

Obviously, insufficient life skills education in the formal curriculum implies that adolescent mental health cannot be adequately protected. This comment is substantiated by the rising mental health concerns in adolescents, such as Internet addiction and depression (Shek and Siu 2019c; Lo et al. 2019). Besides, research showed that adolescent life satisfaction declines and hopelessness increases during adolescent years (Shek and Liang 2018).

The present study clearly suggests that there is an urgent need to review life skills education in Hong Kong. In a review of life skills education in different societies, UNICEF (UNICEF 2012) identified problems in implementing life skills education. Similar challenges, such as lack of systematic planning, policy formulation and validated curriculum, were also highlighted by researchers in Hong Kong (Shek et al. 2018; Shek and Leung 2018). Furthermore, policy makers and educators should tap on validated and evidencebased life skills education programs such as the Project P.A.T.H.S. in Hong Kong (Shek 2019; Shek and Sun 2013; Ma et al. 2018; Ma et al. 2019) which has been regarded as the only evidence-based positive youth development program in different Chinese societies (WHO 2016; Alvarado et al. 2017). Finally, the observation of adult-adolescent discrepancies in related perceptions suggests that adolescents may over-estimate and/or adults may under-estimate life skills in adolescents. The present findings suggest that it is desirable to have more dialogues and an improved understanding of the importance of life skills amongst different stakeholders involved. Although discrepancy in parent-child perceptions has been regarded as "noise" in measurement, research findings suggest that it influences child developmental outcomes. For example, differences in perceptions of parenting characteristics between parents and adolescents were related to developmental outcomes in young people experiencing economic disadvantage (Leung and Shek 2014); differences in perceptions in parents and adolescents on parental sacrifice was also related to achievement motivation of poor Chinese adolescents (Leung and Shek 2016). 
There are several limitations of the present paper. First, while the subjects in Study 1 (i.e., longitudinal study) were randomly selected, subjects in Study 2, 3 and 4 were recruited via convenience sampling. Although the sample sizes in Study 3 and Study 4 were respectable (because it is not easy to recruit teachers and parents in Hong Kong), replication of the findings is needed. Second, regarding the need for life skills education and related sufficiency, only single items were used. It would be desirable to use more items to understand related issues. Third, we did not ask for the "why" of life skills education in adolescents. It would be illuminating if this area could be explored in the future. Finally, besides studying the respondents' perception of life skills in young people in Hong Kong, it would be helpful to ask the respondents to rate their own life skills and correlate the ratings with their well-being. Despite these limitations, this study underscores the importance of understanding the perceptions of different stakeholders of life skills in adolescents, which echoes the spirit of "partners in life skills education" proposed by the World Health Organization (WHO 2009).

Acknowledgements The 6-wave longitudinal study in the Project P.A.T.H.S. is financially supported by The Hong Kong Jockey Club Charities Trust. The three studies based on high school students, teachers and parents are financially supported by Wofoo Foundation.

Open Access This article is licensed under a Creative Commons Attribution 4.0 International License, which permits use, sharing, adaptation, distribution and reproduction in any medium or format, as long as you give appropriate credit to the original author(s) and the source, provide a link to the Creative Commons licence, and indicate if changes were made. The images or other third party material in this article are included in the article's Creative Commons licence, unless indicated otherwise in a credit line to the material. If material is not included in the article's Creative Commons licence and your intended use is not permitted by statutory regulation or exceeds the permitted use, you will need to obtain permission directly from the copyright holder. To view a copy of this licence, visit http://creativecommons.org/licenses/by/4.0/.

\section{References}

Alicke, M. D., \& Sedikides, C. (2009). Self-enhancement and self-protection: What they are and what they do. European Review of Social Psychology, 20(1), 1-48.

Alvarado, G., Skinner, M., Plaut, D., Moss, C., Kapungu, C., \& Reavley, N. (2017). A systematic review of positive youth development programs in low-and middle-income countries. Washington, DC: YouthPower Learning, Making Cents International Retrieved from http:/www.dmeforpeace. org/peacexchange/wp-content/uploads/2017/09/Systematic-Review-of-PYD-Programs-in-LMICs1.pdf.

Benson, P. L., Scales, P. C., \& Syvertsen, A. K. (2011). The contribution of the developmental assets framework to positive youth development theory and practice. In R. M. Lerner, J. V. Lerner, \& J. B. Benson (Eds.), Advances in child development and behavior (1st ed., pp. 197-230). New York: Elsevier.

Catalano, R. F., Berglund, M. L., Ryan, J. A. M., Lonczak, H. S., \& Hawkins, J. D. (2004). Positive youth development in the United States: Research findings on evaluations of positive youth development programs. The Annals of the American Academy of Political and Social Science, 591(1), 98-124.

Catalano, R. F., Fagan, A. A., Gavin, L. E., Greenberg, M. T., Irwin Jr., C. E., Ross, D. A., \& Shek, D. T. L. (2012). Worldwide application of prevention science in adolescent health. The Lancet, 379, 1653-1664.

Domitrovich, C. E., Durlak, J. A., Staley, K. C., \& Weissberg, R. P. (2017). Social-emotional competence: An essential factor for promoting positive adjustment and reducing risk in school children. Child Development, $88,408-416$.

Ferrari, T. M., Hogue, C. A., \& Scheer, S. D. (2004). Parents' perceptions of life skills development in the 4-H Cloverbud program. The Journal of Exttension, 42(3), 1-7.

Harris, L. W., \& Cheney, M. K. (2018). Positive youth development interventions impacting the sexual health of young minority adolescents: A systematic review. The Journal of Early Adolescence, 38(1), 74-117. 
January, A. M., Casey, R. J., \& Paulson, D. (2011). A meta-analysis of classroom-wide interventions to build social skills: Do they work? School Psychology Review, 40, 242-256.

Lerner, R. M., Lerner, J. V., Lewin-Bizan, S., Bowers, E. P., Boyd, M. J., Mueller, M. K., Schmid, K. L., \& Napolitano, C. M. (2011). Positive youth development: Processes, programs, and problematics. Journal of Youth Development, 6(3), 38-62.

Leung, J. T. Y., \& Shek, D. T. L. (2014). Parent-adolescent discrepancies in perceived parenting characteristics and adolescent developmental outcomes in poor Chinese families. Journal of Child and Family Studies, 23(2), 200-213.

Leung, J. T. Y., \& Shek, D. T. L. (2016). Parent-child discrepancies in perceived parental sacrifice and achievement motivation of Chinese adolescents experiencing economic disadvantage. Child Indicators Research, 9(3), 683-700.

Lo, S. M., Wong, H. C., Lam, C. Y., \& Shek, D. T. L. (2019). An innovative multidisciplinary healthcare model in student mental health: Experience in Hong Kong. Applied Research in Quality of Life. https://doi.org/10.1007/s11482-019-09770-9.

Ma, C. M. S., Shek, D. T. L., \& Chen, J. M. T. (2018). Changes in the participants in a community-based positive youth development program in Hong Kong: Objective outcome evaluation using a one-group pretest-posttest design. Applied Research in Quality of Life, 14, 961-979.

Ma, C. M. S., Shek, D. T. L., \& Leung, H. (2019). Evaluation of a positive youth development program in Hong Kong: A replication. Research on Social Work Practice, 29(7), 808-819.

Meyer, K., \& Wurdinger, S. (2016). Students' perceptions of life skill development in project-based learning schools. Journal of Educational Issues, 2(1), 91-114.

Nasheeda, A., Abdullah, H. B., Krauss, S. E., \& Ahmed, N. B. (2019). A narrative systematic review of life skills education: Effectiveness, research gaps and priorities. International Journal of Adolescence and Youth, 24(3), 362-379.

Prajapati, R., Sharma, B., \& Sharma, D. (2017). Significance of life skills education. Contemporary Issues in Education Research, 10(1), 1-6.

Shek, D. T. L. (2019). Impact of the project P.A.T.H.S. in Hong Kong and China. Neuropsychiatry (London), 9, 2217-2219.

Shek, D. T. L., \& Leung, J. (2018). A study on the development of Chinese students (character, psychosocial competence and behavior): Report no. 4-Moral education at the crossroad. Hong Kong: Department of Applied Social Sciences, The Hong Kong Polytechnic University.

Shek, D. T. L., \& Liang, L. Y. (2018). Psychosocial factors influencing individual well-being in Chinese adolescents in Hong Kong: A six-year longitudinal study. Applied Research in Quality of Life, 13(3), 561-584.

Shek, D. T. L., \& Lin, L. (2017). Trajectories of personal well-being attributes among high school students in Hong Kong. Applied Research in Quality of Life, 12, 841-866.

Shek, D. T. L., \& Lin, L. (2017a). A study on the development of Chinese students (character, psychosocial competence and behavior): Report no. 1 - Views of students. Hong Kong: Department of Applied Social Sciences, The Hong Kong Polytechnic University.

Shek, D. T. L., \& Lin, L. (2017b). Use of foul language among Chinese adolescents: Developmental change and relations with psychosocial competences. Journal of Adolescent Health, 60(9), 313-319.

Shek, D. T. L., \& Ma, C. M. S. (2017). A study on the development of Chinese students (character, psychosocial competence and behavior): Report no. 2 - Views of teachers. Hong Kong: Department of Applied Social Sciences, The Hong Kong Polytechnic University.

Shek, D. T. L., \& Siu, A. M. H. (2019a). "UNHAPPY” environment for adolescent development in Hong Kong [special issue]. Journal of Adolescent Health, 64(6), S1-S4.

Shek, D. T. L., \& Siu, A. M. H. (2019b). Adolescent mental health policy and services in Hong Kong: Seven unresolved problems waiting for solutions [special issue]. Journal of Adolescent Health, 64(6), S5-S9.

Shek, D. T. L., \& Siu, A. M. H. (2019c). Mental health and well-being of adolescents in Hong Kong [special issue]. Journal of Adolescent Health, 64(6), S1-S85.

Shek, D. T. L., \& Sun, R. C. F. (Eds.). (2013). Development and evaluation of positive adolescent training through holistic social programs (P.A.T.H.S.). Singapore: Springer.

Shek, D. T. L., \& Yu, L. (2018). A study on the development of Chinese students (character, psychosocial competence and behavior): Report no. 3 - Views of parents. Hong Kong: Department of Applied Social Sciences, The Hong Kong Polytechnic University.

Shek, D. T. L., \& Zhu, X. (2019). Paternal and maternal influence on delinquency among early adolescents in Hong Kong. International Journal of Environmental Research and Public Health, 16, 1338. https://doi. org/10.3390/ijerph16081338.

Shek, D. T. L., Wu, F. K. Y., \& Leung, H. (2018). A study on the development of Chinese students (character, psychosocial competence and behavior): Report no. 5 - A qualitative study of the views of principals and 
teachers on moral education. Hong Kong: Department of Applied Social Sciences, The Hong Kong Polytechnic University.

Shek, D. T. L., Dou, D., \& Ma, L. K. (2019a). Development and validation of a pioneer scale on service leadership behavior in the service economies. Frontiers in Psychology, 10, article 1770. https://doi. org/10.3389/fpsyg.2019.01770.

Shek, D. T. L., Dou, D., Zhu, X., \& Chai, W. (2019b). Positive youth development: Current perspectives. Adolescent Health, Medicine, and Therapeutics, 10, 131-141.

Shek, D. T. L., Zhu, X., Dou, D., \& Chai, W. (2020). Influence of family factors on substance abuse in early adolescents: A longitudinal study in Hong Kong. Journal of Psychoactive Drugs, 52(1), 66-76. https://doi.org/10.1080/02791072.2019.1707333.

Shek, D. T. L., Lin, L., Siu, A. M. H., \& Lee, B. (2019c). Materialism in Chinese adolescents in Hong Kong: Profiles and socio-demographic correlates. International Journal of Child and Adolescent Health, 12(3).

Shek, D. T. L., Ma, C. M. S., Siu, A. M. H., \& Lee, B. (2019d). Materialism and egocentrism in Chinese adolescents in Hong Kong: Perceptions of teachers. International Journal of Child and Adolescent Health, 12(13).

Shek, D. T. L., Yu, L., Lee, T. Y., Sun, R. C. F., \& Law, M. Y. M. (in press). What are Hong Kong Chinese parents' perceptions of materialism and egocentrism in their children? International Journal of Child and Adolescent Health.

Sun, R. C. F., \& Shek, D. T. L. (2012). Positive youth development, life satisfaction and problem behaviour among Chinese adolescents in Hong Kong: A replication. Social Indicators Research, 105, 541-559.

Taylor, R. D., Oberle, E., Durlak, J. A., \& Weissberg, R. P. (2017). Promoting positive youth development through school-based social and emotional learning interventions: A meta-analysis of follow-up effects. Child Development, 88, 1156-1171.

UNESCO. (2016). 2014 regional study on transversal competencies in education policy and practice (phase II) school and teaching practices for twenty-first century challenges: Lessons from the Asia-Pacific region. ERI-Net Asia-Pacific Regional Policy Series. Paris: United Nations Educational, Scientific and Cultural Organization.

UNICEF. (2012). Global evaluation of life skills education programmes: Final report. New York: United Nations Children's Fund Retrieved from https://www.unicef.org/evaluation/files/USA-2012-011-1_ GLSEE.pdf.

WHO. (2009). Partners in life skills education. Geneva: World Health Organization, Department of Mental Health.

WHO. (2016). INSPIRE: Seven strategies for ending violence against children. Geneva: World Health Organization Retrieved from https://www.who.int/publications-detail/inspire-seven-strategies-forending-violence-against-children.

Publisher's Note Springer Nature remains neutral with regard to jurisdictional claims in published maps and institutional affiliations.

\section{Affiliations}

\section{Daniel T.L. Shek ${ }^{1} \cdot$ Li Lin $^{1} \cdot$ Cecilia M.S. Ma ${ }^{1} \cdot$ Lu Yu$^{1} \cdot$ Janet T.Y. Leung ${ }^{1} \cdot$ Florence K.Y. Wu ${ }^{2} \cdot$ Hilde Leung ${ }^{3} \cdot$ Diya Dou ${ }^{1}$}

1 Department of Applied Social Sciences, The Hong Kong Polytechnic University, Hunghom, Hong Kong, People's Republic of China

2 Faculty of Education, The University of Hong Kong, Pokfulam, Hong Kong, People's Republic of China

3 UOW College Hong Kong, Kowloon Tong, Hong Kong, People's Republic of China 